\title{
Transformation Research on Teaching Practice Mode of Physical Education Major Based on Applied-oriented Talents Cultivation
}

\author{
Yong-Kui Zhang \\ School of Physical Education, Tianjin University of Sport, Tianjin, CHINA
}

Received 15 July 2017 • Revised 28 August 2017 • Accepted 1 October 2017

\begin{abstract}
Objective: Social sports is an emerging major, its teaching works in various aspects just start and so need teacher and students to make further improvement and perfection in new problems of the major. Among them, cultivation of social adaptability in teaching process becomes more important. Research methods: Literature consultation and questionnaire survey are applied to investigation and analyze practice of students in our schools' physical education major in Grade 2011 and 2012. Result shows: With the presently rapid development of Chinese social sports industry and people's increasing demands on fitness, there emerged more sports job vacancy in society. However, social sports major are still in the preliminary stage, students of the major came across many problems in teaching practice process. We should carry out market-oriented talents' cultivation, adjust practical work duration, optimize curriculum setting, discriminate practice base, reinforce supervising link, promote comprehensive quality to provide effective evidence and guarantee for formulating reasonable practical work link in social sports major and strive to improve practical quality of students major in social sports.
\end{abstract}

Keywords: teaching practice, talents cultivation, teaching countermeasure, social sports

\section{INTRODUCTION}

Chinese social sports major have still been a professional discipline as the slowly rising sun. Though it is relatively new, it has a promising start. The popular mass sports have facilitated the emergence and prosperity of social sports. The success of Beijing Olympic Games in 2008 and spread of national fitness has further promoted to Chinese social sports major is development. It is believed that social sports major would have huge potential and wide prospects (Zhang \& Wang, 2008). As social sports develop under the promotion of social progress, social sports major in our school have also entered into fast development stage. As the major is emerging, its teaching work in various aspects just starts, so that needs teacher and students' efforts to improve and perfect new problems thereof. Thus, we make feasible research on social sports practice in our school, evaluate and summarize status and future transformation road, which is of realistic and profound significances in the reform of our schools' social sports practice.

\section{Research Background and Status}

In investigation, the paper totally consulted that 1066 journal articles related to social sports major through searching key words "Social sports major" from Wanfang database, whereas only 63 ones related to social sports practice (Chen, 2007). Through repeatedly reading and thinking these journals, I recognized formers' focus, and would like to state my personal views and theories through finding new research views with the formers' help in

(C) Authors. Terms and conditions of Creative Commons Attribution 4.0 International (CC BY 4.0) apply. Correspondence: Yong-Kui Zhang, School of Physical Education, Tianjin University of Sport, Tianjin 300381, China. Ykzhang@126.com 


\section{Contribution of this paper to the literature}

- Teaching practice is the first link in university students' contact with the society. Only do a good job in researching and penetrating through on the teaching practice, we then can provide reliable and effective methods and suggestions on social sports practice transformation to make contributions to our broad groups of students' practical work.

- On the basis of students' practice response, we brainstorm, stand on market demands, focus on students' practice situation and summarize experience and lesson by optimized adjustment on internship duration, reinforcing supervision link, promoting comprehensive quality, discriminating practice base and other effective means, timely solve various problems and explore a road of professional practice that adapts to social progress and talents-job requirements.

the way of learning their research views and methods. By researching results, it is clear that society and scholars have attached great attention to social sports major, which also suggested the important role of the major in society and academic research (Zhang, 2017). However, documents related to "Our school's social sport major "were only four, and even little in studies on our school's social sports practice. By searching documents, it is clear that society and relevant scholars have increased focus on social sports major, there showed an increase demand on it (Zhang \& QIN, 2012); however, research targeted at our school's social sports practice were relatively insufficient, which also becomes an important evidence for the paper's selective research.

In 2007 "Chinese universities' social sports professionals' employment status investigation", Zhangyu Chen suggested that there were lower proportion of social sports graduate students engaging in social sports work (Chen \& Zhang, 2016). By analyzing employment influential factors, there was disconnection between cultivation goals and social demands, non-standard job setting, non-conformance between graduate students' concept of employment and market demands (Zhang, 2008). Thus, he put forward we should combine employment market, school with development of students, and expand space of students' employment and development.

In 2007" Analysis of problems in Chinese social sports development status", Jinlong Li and Shuhong Wang made investigation on university cultivation mode, teaching conditions, students' resources quality, professional thinking and employment situation by questionnaire survey and literature consultation. As the investigation only targeted at leaders and teachers in universities and not go deeper into studying students' subjective factors, it had certain constraints (Zhang \& Peng, 2017). In the paper, it put forward that "external challenges for social sports development were insufficient cultivation of employment market, extremely imbalance distribution in employment areas, especially for little proportion of the number of employees in graduate students from middle and western regions" (Yuan \& Wei, 2011). It went deeper into observation on employment regional distribution of graduate students in social sports major.

In 2001"Universities' social sports establishment status and development countermeasure and suggestions", Jun Liu regarded "universities that set up social sports major in Jiangsu province" as investigation research objects, analysed problems of social sports from university cultivation, curriculum setting and faculty construction (Yang, 2012). In the paper, it pointed out the importance of teachers' internal and external resources' sharing and practical work.

In 2013 “Sichuan provincial Universities' physical education professional teaching and learning status and countermeasure study", Jing Shi carried out investigation and analysis of Sichuan provincial universities physical education major's preparation stage before teaching, practical work implementation stage and assessment and summarization stage after practical work, found out problems and causes in practical work of physical education major in Sichuan province (Fan \& Wang, 2012). So that provided some new thoughts and theoretical supports for Sichuan provincial universities physical education major is teaching practice and undergraduate students' comprehensive abilities better adapting to social development. 


\section{Research Objectives and Significances}

Chinese social sports major have still been a professional discipline as the slowly rising sun. Though it is relatively new, it has a promising start. Social sports are a part in Chinese sports industry, its construction and booming is and would be an important implementation direction for Chinese sports industry (Liu et al., 2011). Social sports major aims to cultivate special talents in social sports and its development is closely related to Chinese social sports (Yao, 2006). Under this circumstance, Chinese universities should take compelling obligation to vigorously establish and develop new sports major facing to society. Social sports practical work is an important link in social sports major as it exerts an important impact. Fail in solving problems in social sports practical work would restrict in the further progress of social sports.

Recently, China has shown an increase trend in the number of graduate students, from 2.13 million people in 2003 to 7.49 million people in 2015, increasing 4.5 times in 12 years. However, employment rate of graduate students has always been not optimistic, remaining in around $75 \%$. That is to say, a great part of universities faces with unemployment after graduation. As a new major, social sports bear huge pressure and confront great test under such circumstance. As it is a new major, it also has problems as not profound and perfect practice mode. How to cultivate students to get work smoothly would be common problems in all teachers and students of universities running social sports major (Li et al., 2017). So how to reduce or avoid unemployment in social sports major of our school and always contribute to university students' employment status? The most direct way was school offered students better practical platform and environment through practice mode transformation during the students' practical work, enabling them to get better opportunities, letting them to have a good performance in practical work that was also their first important contact with society, making them to fulfil practice smoothly and then complete employment choice. Teaching practice is the first link in university students' contact with the society (Li et al., 2016). Only do a good job in researching and penetrating through on the teaching practice, we then can provide reliable and effective methods and suggestions on social sports practice transformation to contribute to our broad groups of students' practical work (Fang \& Xia, 2014).

This paper just went preliminary exploration on practice conditions of students in our school's social sports major to find out which aspects transformation should be made in social sports teaching practice mode so that can shape universality students in an all-around way. It summarized specific methods to provide concrete suggestions and reliable guidance for social sports teaching practice transformation, narrowing universities' difficulties during practice period, letting them to walk out campus leisured, fulfill practice and even smoothly find a job.

\section{RESEARCH OBJECTS AND METHODS}

\section{Research Objects}

Research objects are undergraduate students in our school's social sports major in Grade 2011 and 2012.

\section{Research Methods}

\section{Literature consultation}

Search and collect relevant documents by school's library and electronic journals network, analyze and sort out them to provide firm theoretical basis for the paper's research.

\section{Questionnaire survey}

To recognize status of teaching practice in students of our schools' physical education major, we adopted self-compiled "Questionnaire on transformation research on social sports major's teaching practice mode" to survey on our school's graduate students in physical education major in Grade 2011 and 2012. It totally released 
Table 1. Investigation on students' expected teaching practice duration $(\mathrm{N}=115)$

\begin{tabular}{cccccc}
\hline $\begin{array}{c}\text { Expected teaching duration } \\
\text { Grade of undergraduate students }\end{array}$ & Three months & Four months & Half a year & Over half a year & Total \\
\hline Grade 2011 & 3 & 5 & 7 & 23 & 38 \\
\hline Grade 2012 & 4 & 17 & 20 & 36 & 77 \\
\hline
\end{tabular}

120 questionnaires, recovered 118 ones, the recovery rate was $98.33 \%$, from which there were 115 valid ones, and valid rate was $95.83 \%$.

\section{Mathematical statistics}

Sort out recovered questionnaires and use EXCEL software to implement mathematical statistics with questionnaire data.

\section{RESULTS AND ANALYSES}

We defined the specific transformation aspects in social sports teaching practice mode to shape a more allaround university students, through investigation on status of teaching practice of students major in social sports major and make further analysis and research. Then we summarized concrete methods to provide concrete suggestions and reliable guidance for social sports teaching practice transformation, narrowing universities' difficulties during practice period, letting them to walk out campus leisured, fulfill practice and even smoothly find a job.

\section{Investigation on Teaching Practice Duration}

In Our school's physical education institute cultivation plan in 2011, there defined one term as teaching practice stage that was the seventh term, totally four months. However, with further implementation of teaching practice, exchange with practice units and feedback of students, there showed shorter teaching practice duration. As shown in Table 1, intern students in Grade 11 an 12 generally hoped that teaching practice could be longer so that easier to connect with students' teaching practice with work after graduation. When students entered into practice units, most of them took practice at fixed posts. When they just got into the role and worked on track through training and learning in earlier stage, they would face with the end of teaching practice. As far as students are concerned, in this way, they could not effectively arrange working tasks, which increased their difficulties during teaching practice and affected their quality and efficiency in teaching practice. Similarly, for practice units, they would face with repeated training tasks-just trained students should leave without really getting into work state whereas next a group of intern students would enter into school.

\section{Investigation on Students' Satisfaction with Practice Units}

From our school's cultivation goals on students, there are mainly two choices on practice units, first is working as fitness advisor in fitness club-implementing physical training on students; secondly is working as membership consultant in fitness club, selling and consulting.

By questionnaire survey, it shows that students' satisfaction with practice units' hardware distribution reached $68 \%$, that with their software facilities reached $58 \%$, and that with their treatment reached $60 \%$. Basically, students showed approve with regard to satisfaction with practice units (can refer to Table 2), but some students also reflected their disapproval toward practice units' environment and post setting, mainly reflecting in inconsistency between work in practice units and major in school. This caused students' in adaptation and difficulties in accepting teaching practice occurred in work. Secondly, in the regard of practice unit treatment, individual units' lodging and salary could not satisfy students' expectation, causing them feeling down and reducing their working efficiency. Finally, in training of teaching practice of practice units, some units could not arrange pre-job training on students as required, even required students to directly start working, causing greater difficulties in their practical work and seriously affecting their quality in practical work. 
Table 2. Investigation on students' satisfaction with practice units $(N=115)$

\begin{tabular}{|c|c|c|c|c|}
\hline Practice units' various comprehensive indicators & Satisfied & Percentage & Dissatisfied & Percentage \\
\hline Practice units' hardware distribution (region, site etc.) & 79 & $68 \%$ & 36 & $32 \%$ \\
\hline $\begin{array}{c}\text { Practice units' software facilities( management standard, } \\
\text { training of teaching practice) }\end{array}$ & 67 & $58 \%$ & 48 & $42 \%$ \\
\hline Practice units' treatment(lodging, salary ) & 69 & $60 \%$ & 46 & $40 \%$ \\
\hline Practice units' post( whether consist with major) & 44 & $38 \%$ & 71 & $62 \%$ \\
\hline Achievement of teaching practice & 47 & $40 \%$ & 68 & $60 \%$ \\
\hline
\end{tabular}

Table 3. Investigation on teaching practice efficiency influence factors $(N=115)$

\begin{tabular}{|c|c|c|c|}
\hline Influence factors & Frequency of selection & Percentage & Ranking \\
\hline Disconnection between classroom teaching and practice & 98 & $85 \%$ & 1 \\
\hline Deficiency in personal professional skills & 66 & $57 \%$ & 6 \\
\hline Insufficient ability of contacting with customers & 77 & $67 \%$ & 5 \\
\hline Change concepts of teaching practice & 88 & $76 \%$ & 3 \\
\hline Lack of effective training in practice units & 89 & $77 \%$ & 2 \\
\hline Teaching treatment and welfare & 78 & $68 \%$ & 4 \\
\hline Others (city distribution, traffic etc.) & 56 & $48 \%$ & 7 \\
\hline
\end{tabular}

Table 4. Investigation on Students' opinions on reinforcing teaching practice $(\mathrm{N}=115)$

\begin{tabular}{|c|c|c|c|}
\hline Students opinions on reinforcing teaching practice & Frequency of selection & Percentage & Ranking \\
\hline Further discrimination and selection on practice base & 79 & $69 \%$ & 1 \\
\hline Increase institute's negotiation and exchange with practice units & 76 & $66 \%$ & 2 \\
\hline Organize courses adapt to teaching practice & 65 & $56 \%$ & 4 \\
\hline Further optimization on teaching practice duration & 45 & $39 \%$ & 6 \\
\hline Leading teacher's guidance at any time & 68 & $58 \%$ & 3 \\
\hline Others & 58 & $50 \%$ & 5 \\
\hline
\end{tabular}

\section{Analysis of Teaching Practice Link Influential Factors}

As shown in Table 3, "Investigation on students' personal factors that affect teaching practice efficiency" indicated that disconnection between classroom teaching and practice reached $85 \%$, change concept of teaching practice reached $76 \%$. Main factors that affected teaching practice was difficulty in students' role transformation, regarding themselves as a social worker; in addition, their deficiency in personal professional skills caused them could not solve sports fitness room's fitness guidance and membership consultant problems; during teaching practice process, students may not well observe and think changes in work, especially many students had shortage in exchanging with customers and even lacking of service consciousness during the practice process in fitness club.

\section{Investigation on Teaching Practice Management Link}

Through questionnaire survey, it is clear that students' opinions on further discriminating practice bases reached as high as $69 \%$ and rate of their opinions that hoping institute to increase negotiation and exchange with practice units arrived at $66 \%$. Teaching practice management link is indispensable in teaching practice; good management would contribute to promote quality of teaching practice. In the entire teaching practice management process in our school's social sports major, school has taken a series of measures, such as mobilization before practice, leading a team to enter into practice units, arrange intern students' post, introduction to practice units, paying a regular return visit and feedback, implementing teaching practice closure report and so on. Meanwhile, there are one to two teachers in every practice unit as person-in-charge for teaching practice; they would timely learn students' problems in practice at each stage, and meanwhile offer timely help and solution to the problems. However, questionnaire survey on intern students showed that students' low recognition on teachers' guidance shortly. This may be because some students' practice units were far that the teachers could not learn work situation and solve problems at any time, as shown in Table 4. 
Table 5. Investigation on students' opinions on reinforcing professional course construction $(N=115)$

\begin{tabular}{cccc}
\hline Course learning should be reinforced in students 'opinions & Frequency of selection & Percentage & Ranking \\
\hline Speaking English communication & 34 & $30 \%$ & 4 \\
\hline Practical computer operation ability & 24 & $21 \%$ & 6 \\
\hline Etiquette education, interpersonal communication & 89 & $77 \%$ & 1 \\
\hline Property management knowledge & 6 & $5 \%$ & 9 \\
\hline Secretary relevant ability & 18 & $16 \%$ & 7 \\
\hline Learning and practice of various laws and regulations & 25 & $21 \%$ & 5 \\
\hline Learning of public security and fire-fighting knowledge & 15 & $13 \%$ & 8 \\
\hline Reinforcement and practice of professional skills & 84 & $73 \%$ & 2 \\
\hline Chinese social sports development trend & 76 & $66 \%$ & 3 \\
\hline
\end{tabular}

\section{Investigation on Curriculum Setting of Social Sports Major}

As shown in Table 5, "Investigation on reinforcing construction of students' professional courses" indicated that students' selection ratio in etiquette education and interpersonal communication reached $77 \%$, suggesting that students were keen for strengthening training on social communication and etiquette. Our school's physical education institute began to recruit undergraduate major in social sports since 2007; the major was new in our school. Thus, there haven't formed individual unique advantage in social sports curriculum system structure, setting, module selection and professional teaching practice link, especially not completely getting rid of physical education course constraints in teaching course setting. The major's characteristic may not reflect accordingly. By questionnaire survey on intern students, it showed that students thought that social sports major should reinforce some courses, such as etiquette education, interpersonal communication. This reflected that students realized that they should not only master enough professional knowledge and skill after entering into society, but also learn how to get on well with others and realized interpersonal communication was also an important wealth during teaching practice. In addition, at the same time, reinforcement should be made on professional skills and practice as well as China's social sports development trend. Feedback of students' teaching practice link would enable us to make proper professional course choices.

\section{COUNTERMEASURE RESEARCH}

Through investigation on practice conditions of students in Grade 2011 and 2012, we found that there are many problems in their teaching practice. If the problems could not be effectively solved, the goals in students' cultivation may not reach while also definite professional, application and peculiarity in social sports may not realize. Undefined social sports major's teaching practice cultivation mode made students not be able to combine theory with practice, causing difficulties in students' judgment and positioning on their employment and future development. We should think about problems in teaching practice, find out social sports characteristic teaching practice mode from problems, and enable the major to develop for a long time.

\section{Change Students' Concept of Teaching Practice}

Through studying on questionnaire, we found that students in social sports major would be dispirited in case that they were hard to get help from school and would further affect their teaching practice. With regard to this, school should attach great attention, hold mobilization meeting before students' starting teaching practice, firstly it should have students learnt that they were regular labors with knowledge and ability. Having recognized current serious employment environment, students would upright their attitude towards teaching practice, regard the practice as an opportunity to examine their ability in four years' university life from heart. By doing so, the teaching practice would build firm practical operation base for university students' future work, and students in turn should positively reflect their behaviors in practice process, find out shortcomings and correct so as to constantly perfect themselves. 


\section{Strengthening Management Link in Teaching Practice Stage}

By far, our school's social sports major has took a long teaching practice duration with rather scattered practice sites, advisors may not stay with students for a long time to guide and manage students' practice, which in fact led to shortage of necessary supervision in the overall teaching practice, and even partial of practical work were left alone. Facing with this problem, school should arrange one to two teachers as person-in-charge to communicate with institute, in addition, they should also adopt irregular visiting, consulting with practice units by phone, strengthen exchange between school and practice base to learn students' overall performance during practice. At the same time, the school should regularly do spot checking on students by telephone to learn their recently actual situations, carry out timely coaching and help on students came across difficulties, making the whole teaching practice well supervised and information opened.

\section{Further Discriminate Practice Bases, Realize the Survival of the Fittest}

By investigation on students, we found that most of the students were unfair treated in practice sites during practice period, or they could get no benefits to their future development in practical work. Some practical units even treated intern students as normal employers, letting them to work in fixed and single post to implement repeated simple work. Teaching practice is also a comprehensive practical teaching. The aims of teaching practice could not surely reach if regarding teaching practice as a general labor relationship between school and practice units, let students to go in for simple and repeated work in the same post and even non-major work. Thus, in the selection of practice base, school should conduct meticulous investigation and go deeper into field visiting from multiple aspects and multi-perspective; besides, they should determined remove practice units that could not guarantee for requirements and impair students' interest. School should ensure quality of teaching practice, and meanwhile steadily exploit construction on social sports practice bases.

\section{Be a Strong Support of Intern Students, Guarantee for Students' Basic Interests}

In investigation on students' teaching practice situation, we also found that individual practice unit could not provide welfare treatment in time as stipulated in signed agreement, and even increased work load and extended working time randomly in work. All of these seriously impaired students' basic interests, caused certain economic loss for students and even led to students' resistance to practice units as the worst and leaving out of work without permission. Therefore, teachers in institute should frequently communicate with students. In case of contradiction occurred to practice units and students, the teachers should hurry to students' practice unit at the first time to learn the causes of such matter and students' willing, and then negotiate with the units as "official", argue strongly on just grounds, guarantee for students' basic interests and be a strong support of them.

\section{Promote Students' Comprehensive Ability in an All-around Way, Strengthen Cultivation of Comprehensive Quality}

With feedback of investigation on students' teaching practice conditions, most of the students during the teaching practice period generally reflected that they should strengthen personal comprehensive quality, reinforce learning on the application of occupational skills, and meanwhile need to acquire more certificates on various occupational skills, further combine with relevant knowledge contents and skills of professional certificate, and promote their comprehensive ability to solve practical problems. During teaching practice, university students would reassure practice unites and customers if they work with relevant certificate. Besides, they should learn some basic skills, such as basic standard of essay writing and social etiquettes.

\section{Reinforce Team Construction of Faculty Advisors}

At present, most of lecturers in our school's social sports courses are originated from school physical education major, they are hard to overcome existing knowledge system to pass on knowledge to students targeted at characteristics in social sports major. This would lead to some drawbacks in students' major in social sports in 
the application of sports skills and theoretical knowledge. Therefore, we should further train in-service social sports teachers, and adopt the way as "going out and coming in" to conduct professional social practice training to help sports teachers to get rid of fixed thinking mode, find out scientific and reasonable teaching methods; we could train them by getting them into social practice, the teachers could go to fitness club, resident community and other sports activity places to carry out in-situ simulation teaching and systematic training in spare time, so that help students to master more fixed social practical skills with personal experience.

\section{CONCLUSIONS}

Every discipline would come across many problems in the beginning of establishment and development. Social sports are set to cultivate social sports professionals, its development level and conditions would seriously impact on Chinese sports undertakings. Therefore, Chinese universities must take compelling obligations to strive to establish and develop new social-oriented sports major. For our school's social sports existing teaching practice mode, we should base on students' practice feedback, brainstorm, stand on market demands, focus on students' practice situation and summarize experience and lesson by optimized adjustment on internship duration, reinforcing supervision link, promoting comprehensive quality, discriminating practice base and other effective means, timely solve various problems and explore a road of professional practice that adapts to social progress and talents-job requirements so as to cultivate new generation sports talents with high quality and comprehensiveness application for Chinese education.

\section{REFERENCES}

Chen, C., \& Zhang, B. (2016). Factor analysis in optimizing the structure of the sports industry. In: Z. Henan and J.Y. Beijing, eds. 2016 National Convention on Sports Science of China, Zhengzhou China, Sep 23-25 2016. France: EDP Sciences. doi:10.1051/ncssc/201701013

Chen, Z. Y. (2007). Job market for university social sports graduates. Journal of Wuhan Institute of Physical Education, 41(11), 78-80. doi:10.3969/j.issn.1000-520X.2007.11.018

Fan, M. Y., \& Wang, Y. (2012). Prospective on the Employment of Leisure Sports Professionals of China's Sports Universities. Journal of Jilin Institute of Physical Education, (2), 95-97. doi:10.3969/j.issn.16721365.2012.02.029

Fang, W., \& Xia, Y. J. (2014).The Rethinking of Social Sports Professional Personnel Training in Colleges and Universities. Journal of Hubei Sports Science, (5), 456-458.

Li, F., Liu, L., Wang, Q. H., Qin, K. L., Hu, Q. Q., Yang, Q., Liu, Y. N., \& Zhang, B. (2016). Tennis balls judgment model based on numerical simulation. In: Z. Henan and J.Y. Beijing, eds. 2016 National Convention on Sports Science of China, Zhengzhou China, Sep 23-25 2016. France: EDP Sciences. doi:10.1051/ncssc/201701018

Li, X. P., Xu, M. H., Zhao, F. N., Zhang, L., \& Zhang, G. Z. (2017). Research on the Construction of Ecological System of Internet Learning Resources for Postgraduates. Academic Degrees E Graduate Education, (4), 26-30. doi:10.16750/j.adge.2017.04.006

Liu, C. M., Li, Z. H., \& Ren, P. (2011). A Research on Curriculum Reform of Social Sports Major Directed by Social Needs in China. Journal of Hebei Institute of Physical Education, 25(5), 44-47. doi:10.3969/j.issn.10083596.2011.05.012

Yang, J. C. (2012). Analysis on Prospects of Social Sports Professional Employment. Bulletin of Sport Science $\mathcal{E}$ Technology, 20(5), 123-125. doi:10.3969/j.issn.1005-0256.2012.05.054

Yao, W. (2006). New orientation of training objectives for university social sports majors. Journal of Wuhan Institute of Physical Education, 40(10), 90-93. doi:10.3969/j.issn.1000-520X.2006.10.022

Yuan, Y., \& Wei, Z. Q. (2011). Status and countermeasure of social sports graduates from colleges and universities of Shanghai. Journal of Shandong Physical Education Institute, 27(8), 86-91. doi:10.3969/j.issn.10062076.2011.08.019

Zhang, B. (2008). Design and application effect of campus orienteering maps. Journal of Wuhan Institute of Physical Education, 42(10), 94-94. doi:10.3969/j.issn.1000-520X.2008.10.019 
Zhang, B. (2017). Research on the Development and Change of Chinese Sports Science Based on Bibliometric Analysis. Eurasia Journal of Mathematics Science and Technology Education, 13(10), 6407-6414. doi:10.12973/eurasia.2017.01073a

Zhang, B., \& Peng, P. (2017). Research on the Development of Education Resources for the Internet Plus Universities in the National Health Field. Eurasia Journal of Mathematics Science and Technology Education, 13(8), 50855093. doi:10.12973/eurasia.2017.00984a

Zhang, B., \& Qin, X. P. (2012). “Use money to buy service”: new ideas for sports basic public service provision mechanism. Journal of Shandong Institute of Physical Education and Sports, 28(5), 6-10. doi:10.3969/j.issn.10062076.2012.05.002

Zhang, Y. Y., \& Wang, Z. (2008). Construction and Practice of Wushu Specialty Talent-Training Pattern Established with Idea of "Being Versed in Three Skills". Journal of Shanghai Physical Education Institute, 32(3), 88-91. doi:10.3969/j.issn.1000-5498.2008.03.023

\section{http://www.ejmste.com}

